\title{
The technology of selecting gifted children in combat sports based on comprehensive monitoring of conditions of athletes
}

\author{
Yury Glebov ${ }^{1}$, Anatoliy Khorunzhiy ${ }^{1}$, Boris Podlivaev $^{2 *}$, Aleksandr Kuznetsov ${ }^{3}$ \\ ${ }^{1}$ Smolensk State College Olympic Reserve, 214004, Smolensk, Russia \\ ${ }^{1}$ Federal Center of Sports Reserve Training, 105064, Moscow, Russia \\ ${ }^{2}$ Chaykovskiy State Institute of Physical Culture, 617764, Chaykovskiy, Russia
}

\begin{abstract}
The problem of 12-14-year-old athletes' selection that are engaged in combat sports is one of the most urgent problem of training the sports reserve. The search for gifted children and teenagers is in fact the most important factor for high achievements in the chosen sport. According to V. p. Guba [2], many experts understand sports selection as an assessment and recognition of children's individual predisposition to achieve in a particular sport based on their inclinations, abilities, and gifts. However, the components of athletic giftedness used in sports-oriented selection differ significantly in the available research. $[1,3,4,5,6,7]$. Federal State Budget Establishment Professional Educational Organization "Smolensk State College of Olympic Reserve" (referred to as FSBE PEO "SSCOR") and Smolensk Regional Fund "Social development" conduct the research for selecting sports - gifted children that are engaged in martial arts. The research is held on the proposed technology and is based on comprehensive monitoring of the athletes condition. This technology allows to ensure the balance between high loads and maintaining health, increase the effectiveness of the training process, predict the achievement of the fitness form peak and maintain it throughout the competition period.
\end{abstract}

\section{Introduction}

There is no conclusion what methods to use when determining certain properties of an athlete physiological and nervous systems. The proposed method of testing the physiological and psychomotor abilities of sports-gifted 12-14 year-old athletes will allow to determine the degree of the planned load and it, in its turn, will increase the effectiveness of the training process.

The competitive activity in combat sports requires from the young athletes to display a high level of physical, functional and psychophysical capabilities that contribute to the advantage over the opponent in the fight. Largely these components determine the state of health. It is one of the most priority areas in children's and youth sports in conjunction with the achievement of high sports results.

The purpose of our research is to study the level of psychophysiological abilities of 12-14 year-old athletes that are engaged in martial arts and the improvement of the selection and the educational process in sports schools for youth.

\section{Materials and Methods}

Young wrestlers were involved in the studies of the experimental (innovative) project on the basis of Olympic Reserve.

In total 134 athletes were examined during the III All-Russian Wrestling Festival "Youth of Russia" (February 1020, 2020, Smolensk, Russia). The Festival was held for the students of educational organizations that are engaged in martial arts in sports and fitness organizations of the Central Federal District of the Russian Federation.

The dynamics of young athletes functional capabilities indicators was carried out according to the method of "Simple visual-motor reaction" that evaluates performance by the functional level of the system.

Diagnostic procedures were based on a neurodynamic analysis of heart rate variability (referred to as HRV) with the help of the OMEGA-C complex that is a new information technology for analyzing cardiorhythmological processes of the organism.

\section{Results and Discussion}

The obtained sensorimotor response data are reasonably used in psychophysiological research. Objectively they reflect the functional state of the central nervous system, the nature and dynamics of indicators, both mental and physiological processes.

\footnotetext{
${ }^{*}$ Corresponding author: podlivaevb@mail.ru
} 
During the research all young athletes underwent a psychophysiological examination according to a standard set of methods mentioned above, designed for comprehensive monitoring of the central nervous system functional state and heart rate variability (table 1 ).

Table 1. The dynamics of the psychophysiological testing results 12-14 year-old athletes at competitions

\begin{tabular}{|c|c|c|c|c|}
\hline \multicolumn{2}{|c|}{ Indicator, unit of measurement } & \multicolumn{2}{c|}{ Competitive period } & $\mathrm{p}$ \\
\hline \multirow{3}{*}{$\begin{array}{c}\text { Visual- } \\
\text { motor }\end{array}$} & Reactiom time, ms & CG & EG & $<0,05$ \\
\cline { 2 - 5 } $\begin{array}{c}\text { reaction } \\
\text { record }\end{array}$ & Functional level, standard unit & $242,8 \pm 8,8$ & $217,0 \pm 7,4$ & $>0,05$ \\
\cline { 2 - 5 } & Level of condition, standard unit & $4,1+0,4$ & $5,2+0,2$ & $>0,05$ \\
\cline { 2 - 5 } & $\begin{array}{c}\text { Level of functional work, standard } \\
\text { unit }\end{array}$ & $3,7 \pm 0,08$ & $2,0+0,06$ & $>0,05$ \\
\hline \multicolumn{2}{|r|}{ Vegetative coefficient, standard unit } & $1,51+0,1$ & $3,8 \pm 0,1$ & $>0,05$ \\
\hline
\end{tabular}

Psychophysiological diagnostics of the wrestlers aged 12-14 years showed that there was a significant improvement in the indicators of visual-motor reaction ((further VMRR), reaction of discrimination and the decision time by $23.3 ; 53.7$ and $12 \mathrm{~ms}$, respectively ( $<<0.05$; table 1$)$. In the control group the studied in dicators did not change significantly ( $\mathrm{p}>0.05)$.

It is noteworthy that by the end of the competitive period the psychophysiological indicators of the athletes from the experimental group significantly exceeded the results shown by the athletes from the control group ( $p<0.05$; table $1)$.

During the dynamic observation the balance of the autonomous regulation system was observed. It was indicated by the results of an active orthostatic test (table 2). It was also obvious by the high values of the VNS parasympathetic part reactivity, and a significant increase in indicators characterizing sympathoadrenal activity (LF/HF and the spectral power of the LF component).

Table 2. Indicators of time and spectral analysis of HRV during an active orthostatic test

\begin{tabular}{|c|l|c|}
\hline № & \multicolumn{1}{|c|}{ Indicators } & Average mark \\
\hline 1 & cardiac contractions rate $^{2}$ & $96(83-112)^{*}$ \\
\hline 2 & $\mathrm{TP}, \mathrm{mc}^{2} / \mathrm{Hz}$ & $2722(632-4263)^{*}$ \\
\hline 3 & $\mathrm{LF}, \mathrm{mc}^{2} / \mathrm{Hz}$ & $1094(308-2172)^{*}$ \\
\hline 4 & $\mathrm{HF}, \mathrm{mc}^{2} / \mathrm{Hz}$ & $168(26-576)^{*}$ \\
\hline 5 & $\mathrm{LF} / \mathrm{HF}$ & $6,9(2,0-15,5)^{*}$ \\
\hline 6 & $\mathrm{LF}, \%$ & $47,9(30,0-61,1)^{*}$ \\
\hline 7 & $\mathrm{HF}, \%$ & $7,5(2,8-17,9)^{*}$ \\
\hline
\end{tabular}

$\mathrm{TP}$ - the total power of the heartbeat spectrum

Thus, the features of heart rate variability of wrestlers include the following indicators: high activity of both the parasympathetic and sympathetic parts of the VNS, the total power of the spectrum (TP) - more than $2500 \mathrm{~ms}^{2} / \mathrm{Hz}$, the balance of the sectors of VNS (LF/HF) - from 0.5 to 1.5. These three indicators of spectral power (TP, LF/HFVLF, \%) are the most informative when evaluating and interpreting HRV indicators.

The value of TP reflects the variability of the heart rate. It is possible to judge the preservation of good and satisfactory functional state of the body by the value of TP. The LF/HF ratio allows us to characterize the balance of the VNS sections. VLF, \% reflects the contribution of cerebral ergotropic structures to heart rate modulation.

The simplicity and speed of HRV assessment make this method an indispensable method for rapid control of the developing pathological abnormalities probability.

\section{Conclusions}

1. The results of our research showed that at the moment young wrestlers as a rule have a low level of the psychomotor abilities development. According to many experts these abilities are the foundation in achieving high sports results and without their harmonious development the capabilities of young athletes are extremely limited.

2. Evaluation of HRV indicators allows to approach the scientific forecasting of physical capabilities, to solve the problem of selecting sports gifted children for martial arts, to build a training schedule more rational and to monitor the functional state of athletes.

3. The dynamic monitoring of 12-14 years athletes using the Omega-C complex technology throughout the training cycle allows to:

- significantly increase the effectiveness of training

- reduce the risk of injuries and the occurrence of diseases

- not to permit athletes to compete if there is a threat of sudden cardiac arrest. It will prevent the athlete from dying during the competition.

4. New unique methods of physical activity intensity and duration individual selection can be created with constant monitoring of both the physical and mental state of children specializing in martial arts. 


\section{References}

1. Yu.A. Glebov, A.N. Khorunzhiy, B.A. Podlivaev, The role of experimental and innovative activities in the development of the sports reserve training system. Materials of the all-Russian scientific and practical conference, Siberian state University of physical culture and sport, Omsk, November 14-15, 2019 (Omsk : Sibgufk Publishing House, 96-100, 2019)

2. V.P. Guba, Theory and practice of physical culture, 2, 62-64 (2008)

3. A.S. Kuznetsov, Physical culture: upbringing, education, training, 1, 30-32 (2002)

4. V.A. Salnikov, Theory and practice of physical culture, 4, 16-20 (2002)

5. A.S. Kuznetsov, The Russian Journal of Physical Education and Sport, 13(1), 16-26 (2018)

6. A.A. Khorunzhiy, The role of experimental and innovative activities in the development of the sports reserve training system: materials of the all-Russian scientific and practical conference, Siberian state University of physical culture and sport, Omsk, November 14-15, 2019 (Omsk : Sibgufk Publishing House, 374-379, 2019)

7. A.N. Khorunzhiy, The role of experimental and innovative activities in the development of the sports reserve training system: materials of the all-Russian scientific and practical conference, Siberian state University of physical culture and sport, Omsk, November 14-15, 2019-(Omsk, Sibgufk Publishing House, 380-384, 2019) 